\title{
REGIÕES HOMOGÊNEAS DE VEGETAÇÃO UTILIZANDO A VARIABILIDADE DO NDVI
}

\author{
VEGETATION HOMOGENEOUS REGIONS USING NDVI VARIABILITY
}

\author{
Ana Paula Assumpção Cordeiro ${ }^{1}$ Moacir Antônio Berlato ${ }^{2}$ Denise Cybis Fontana ${ }^{1}$ \\ Ricardo Wanke de Melo $^{2}$ Yosio Edemir Shimabukuro ${ }^{3}$ Claudimar Sidnei Fior ${ }^{4}$
}

\begin{abstract}
RESUMO
As técnicas de classificação, como a análise de agrupamento, utilizadas nas áreas biológicas, em chaves de classificação de plantas e animais, também são úteis para definição de regiões homogêneas, seja para dados climáticos ou para identificação ou monitoramento da vegetação. O objetivo desse trabalho foi caracterizar a dinâmica espaço-temporal do Índice de Vegetação por Diferença Normalizada (NDVI) dos grandes grupos vegetais do Rio Grande do Sul, agrupar regiões homogêneas com base na variabilidade temporal do NDVI e analisar o padrão de variabilidade anual do NDVI dos diferentes grupos. Para tanto, foram utilizados dados de NDVI da série Global Inventory Modeling and Mapping Studies (GIMMS), derivadas do Advanced Very High Resolution Radiometer / National Oceanic and Atmospheric Administration (AVHRR/NOAA) do período de janeiro de 1982 a dezembro de 2008. Foram definidos seis grupos, os quais foram comparados ao macrozoneamento ambiental do Estado. Os resultados mostraram que a variabilidade de NDVI, obtida da série GIMMS/AVHRR, permite agrupar regiões homogêneas, de forma a identificar e mapear os principais grupos vegetais que ocorrem no estado do Rio Grande do Sul. Os grupos são caracterizados por um padrão sazonal típico, porém, com variações de amplitude de NDVI entre eles, o que possibilita monitorar as variações fenológicas da vegetação em decorrência da sua dinâmica temporal.
\end{abstract}

Palavras-chave: índice de vegetação; análise de agrupamento; Rio Grande do Sul.

\section{ABSTRACT}

The classification techniques, such as cluster analysis, used in biological areas, in the plants and animals classification keys, are also useful for defining homogeneous regions, for climate data or for identification or monitoring of vegetation. The objective of the research was to characterize the spatiotemporal dynamic of NDVI (Normalized Vegetation Index Difference) of vegetation groups of Rio Grande do Sul, clustering homogeneous regions based on NDVI temporal variability and to analyze the pattern of NDVI annual variability of the different groups. For this NDVI data from the Global Inventory Modeling and Mapping Studies (GIMMS) series, derived from Advanced Very High Resolution Radiometer / National Oceanic and Atmospheric Administration (AVHRR/NOAA) over the period from January 1982 to December 2008 were used. Six groups were defined, which were compared to environmental macrozoning. The results showed that the variability of NDVI, obtained from GIMMS/AVHRR series, allows clustering homogeneous regions in order to identify and map the main vegetation groups that occur in the Rio Grande do Sul

1 Engenheira Agrônoma, Dra ., Departamento de Plantas Forrageiras e Agrometeorologia, Faculdade de Agronomia, Universidade Federal do Rio Grande do Sul, Av. Bento Gonçalves, 7712, CEP 91540-000, Porto Alegre (RS), Brasil. apacufrgs@gmail.com / dfontana@ufrgs.br

2 Engenheiro Agrônomo, Dr., Professor do Departamento de Plantas Forrageiras e Agrometeorologia, Faculdade de Agronomia, Universidade Federal do Rio Grande do Sul, Av. Bento Gonçalves, 7712, CEP 91540-000, Porto Alegre (RS), Brasil. moacir.berlato@ufrgs.br / ricardo.wanke@ufrgs.br

3 Engenheiro Florestal, Dr., Pesquisador Instituto Nacional de Pesquisas Espaciais, Divisão de Sensoriamento Remoto, Av. dos Astronautas, 1758, Jardim da Granja, São José dos Campos, CEP 12227-010 (SP), Brasil. yosio@, dsr.inpe.br

4 Engenheiro Agrônomo, Dr., Professor do Departamento de Horticultura e Silvicultura, Faculdade de Agronomia, Universidade Federal do Rio Grande do Sul, Av. Bento Gonçalves, 7712, CEP 91540-000, Porto Alegre (RS), Brasil.csfior@ufrgs.br

Recebido para publicação em 18/09/2014 e aceito em 15/01/2016

Ci. Fl., v. 27, n. 3, jul.-set., 2017 
State. Vegetation groups are characterized by a typical seasonal pattern, however, with amplitude variations of NDVI between them, which allow to monitor phenological changes in vegetation due to its temporal dynamics.

Keywords: vegetation index; cluster analysis; Rio Grande do Sul State.

\section{INTRODUÇÃO}

O monitoramento da dinâmica espaço-temporal da vegetação natural ou de cultivos agrícolas, através de imagens de satélite, vem crescendo a cada década. Isto se justifica porque as imagens, além de permitirem acompanhar o padrão de resposta da vegetação, são fontes consistentes de informações e representativas da variabilidade espacial, em escala regional e até continental. Daí sua importância, visto que oferece subsídios à elaboração de planos de manejo dos recursos naturais e à delimitação de áreas prioritárias para a conservação. No contexto agrícola, o monitoramento da evolução temporal da biomassa, em tempo real, é útil para fins de previsão de safras (FONTANA; BERLATO; BERGAMASCHI, 1998), podendo subsidiar também o acompanhamento da expansão e retração de fronteiras agrícolas.

Dentre os vários índices elaborados para o monitoramento da vegetação, um dos mais utilizados é o Índice de Vegetação por Diferença Normalizada, do inglês, Normalized Difference Vegetation Index (NDVI), obtido através da razão entre a diferença e a soma das reflectâncias no infravermelho próximo e no vermelho (ROUSE et al., 1973). A equação geral do NDVI é representada por:

$$
N D V I=\frac{\left(\rho_{I V P}-\rho_{V}\right)}{\left(\rho_{I V P}+\rho_{V}\right)}
$$

Em que NDVI é o Índice de Vegetação por Diferença Normalizada, $\rho_{I V P}$, a reflectância no infravermelho próximo; e, $\rho_{V}$ a reflectância no vermelho.

Os valores do NDVI podem variar entre -1 e 1, sendo positivos quando os alvos são rochas, solos descobertos e vegetação. Solos descobertos e rochas refletem o vermelho e o infravermelho próximo quase na mesma intensidade, por conseguinte, seu NDVI aproxima-se de zero. Já valores maiores de NDVI estão associados a maiores densidades de vegetação saudável. Alvos que refletem mais intensamente na porção do vermelho em comparação com o infravermelho próximo (nuvens, corpos d'água ou neve) apresentam NDVI negativo.

Definido um perfil de evolução temporal do NDVI típico de uma região, alterações neste perfil têm sido utilizadas para o monitoramento das condições de crescimento e desenvolvimento das plantas, detecção de estresses, estimativa de rendimento de culturas, entre outros. Logo, a utilização de imagens do Advanced Very High Resolution Radiometer / National Oceanic and Atmospheric Administration (AVHRR/NOAA) tem auxiliado no entendimento da dinâmica temporal dos grandes grupos vegetais do Rio Grande do Sul, assim como das diferenças entre estes grupos (JACÓBSEN et al., 2004).

Técnicas de classificação de imagens podem ser usadas para se obter os limites de determinadas regiões de interesse como biomas ou regiões agrícolas. A técnica de classificação de análise de agrupamento consiste em determinar o nível de similaridade ou dissimilaridade entre objetos, aplicando uma função de agrupamento a uma determinada variável (DINIZ, 2002). Basicamente, as técnicas de classificação buscam arranjar um conjunto de objetos (observações), cada um com múltiplos atributos, de forma a agrupar objetos próximos e separar os diferentes. A medida da proximidade entre objetos é determinada pela análise simultânea de todos os atributos de cada objeto em relação aos demais. Existem dois tipos de medidas de proximidade: as medidas de similaridade (e dissimilaridade), que são especialmente adequadas quando os objetos são caracterizados por atributos qualitativos; e as distâncias, que são uma medida especial de dissimilaridade, utilizadas quando os objetos são caracterizados por atributos quantitativos (GURGEL, 2000).

O "K-médias", técnica de classificação não supervisionada, é um algoritmo de agrupamento que usa como critério a soma da distância entre cada pixel e o centro do grupo mais próximo (centroide), visando minimizar o quadrado do erro. O "K-médias" começa pela inicialização de centroides K (meio), atribui cada pixel ao grupo cujo centroide está mais próximo, atualiza os centroides do grupo e, então, repete o processo até que os centroides $\mathrm{K}$ estejam fixos. Uma vez que o seu desempenho depende fortemente da 
estimativa inicial da partição, um número relativamente grande de grupos é geralmente recomendado para adquirir um padrão inicial de centroides o mais completo possível (MIRANDA, 2011).

As técnicas de classificação são muito utilizadas nas áreas biológicas, em chaves de classificação de plantas e animais. Além de seu uso nestas áreas, a análise de agrupamento também é útil para definição de regiões homogêneas, seja para dados climáticos (DINIZ et al., 2003; MARQUES, 2005; LYRA et al., 2006) ou para identificação ou monitoramento da vegetação (GURGEL; FERREIRA; LUIZ, 2003; MOTTA; FONTANA; WEBER, 2003).

Através do método de agrupamento de Ward (WARD, 1963), Lyra et al. (2006) determinaram regiões homogêneas em função da sazonalidade da precipitação pluvial mensal no Estado de Táchira, na Venezuela. Para o Estado do Rio Grande do Sul, a identificação de regiões com comportamentos similares, com relação a dados climáticos, foi realizada por Diniz et al. (2003) e por Marques (2005). Diniz et al. (2003) identificaram regiões homogêneas em função da temperatura do ar (mínima e máxima). Já Marques (2005) definiu regiões homogêneas no Estado em função da precipitação pluvial. As regiões homogêneas, uma vez determinadas, podem servir de subsídio a estudos mais detalhados, como de zoneamentos climáticos e agroclimáticos (DINIZ et al., 2003).

Para monitorar a evolução temporal da cultura da soja no Rio Grande do Sul, Motta, Fontana e Weber (2003) agruparam cinco regiões homogêneas, através da análise de agrupamento hierárquico pelo método de Ward (WARD, 1963), o qual utiliza como medida de proximidade (dissimilaridade) a distância euclidiana. Para tal análise foi considerado, como variável de entrada, o NDVI máximo mensal de imagens do AVHRR/NOAA, em 18 janelas de amostragem, para o período de setembro de 1999 a março de 2000, de forma a identificar grupos com padrão semelhante de evolução de NDVI. Os autores concluíram que a evolução temporal do NDVI-AVHRR/NOAA apresenta sensibilidade quanto às diferenças de uso e cobertura do solo, demonstrando que as escalas (espacial e temporal) das imagens são adequadas para o acompanhamento em nível regional da evolução temporal da biomassa.

Gurgel, Ferreira e Luiz (2003) analisaram a variabilidade do NDVI sobre o Brasil, utilizando-se da análise de agrupamento, com base na distância euclidiana, a partir de imagens mensais da série GIMMS/ AVHRR/NOAA do período de janeiro de 1982 a dezembro de 1993. As imagens do Global Inventory Modeling and Mapping Studies (GIMMS) são derivadas do sensor AVHRR a bordo dos satélites da série NOAA. Esta série vem sendo disponibilizada por um grupo de estudo, formado por pesquisadores da National Aeronautics and Space Administration (NASA) e da Universidade de Maryland (EUA) e se constitui em importante fonte de informações sobre a dinâmica espaço-temporal da vegetação no Globo. Nesse estudo, a cobertura vegetal no Rio Grande do Sul foi classificada em dois grandes grupos, identificados como: campanhas gaúchas (região de estepe do Sul do Brasil) e floresta ombrófila (GURGEL; FERREIR; LUIZ, 2003). Devido ao potencial apresentado pela análise de agrupamento para classificar os grandes grupos de vegetação do Brasil, Gurgel, Ferreira e Luiz (2003) recomendaram aplicar esta técnica nos dados de NDVI, utilizando resolução espacial de $8 \mathrm{~km}$, já que a análise foi feita para uma resolução espacial de $64 \mathrm{~km}$. Segundo os autores, isso possibilitaria uma melhor separação dos diversos tipos de vegetação e, consequentemente, uma melhor compreensão da variabilidade climática associada.

Neste contexto, o objetivo do trabalho foi caracterizar a dinâmica espaço-temporal do NDVI do AVHRR/NOAA dos grandes grupos vegetais do Rio Grande do Sul, agrupar regiões homogêneas com base na variabilidade temporal do NDVI e analisar o padrão de variabilidade anual do NDVI dos diferentes grupos.

\section{MATERIAL E MÉTODOS}

\section{Área de estudo}

As análises abrangeram o Estado do Rio Grande do Sul, que está situado no extremo meridional do Brasil, entre os paralelos $27^{\circ} 03^{\prime} 42^{\prime \prime}$ e $33^{\circ} 45^{\prime} 09^{\prime \prime}$ latitude Sul, e os meridianos $49^{\circ} 42^{\prime} 41^{\prime \prime}$ e $57^{\circ} 40^{\prime} 57^{\prime \prime}$ longitude Oeste, com uma superfície total de $281.748,538 \mathrm{~km}^{2}$ (IBGE, 2002). As maiores altitudes do Rio Grande do Sul são encontradas no nordeste do Estado, nos Aparados da Serra, onde o ponto mais alto está a 1.398 m (IBGE, 2011). Enquanto que as menores altitudes encontram-se junto à costa litorânea do Oceano 
Atlântico, próximas ao nível médio do mar.

Segundo a classificação climática de Wladimir Köppen (KÖPPEN, 1948), o clima predominante no Rio Grande do Sul é o tipo Cfa, subtropical ou temperado quente, e do tipo $\mathrm{Cfb}$ nas regiões de maior altitude do Estado, como a Serra do Nordeste, os Campos de Cima da Serra e a Serra do Sudeste. A temperatura média do ar anual no Rio Grande do Sul é de $18,8^{\circ} \mathrm{C}$ (média do período de 1980 a 2009), variando de $13,3^{\circ} \mathrm{C}$ em julho até $23,9^{\circ} \mathrm{C}$ em janeiro. Os valores médios de temperatura máxima do ar variam de 18,1 a $29,4^{\circ} \mathrm{C}$ e de temperatura mínima do ar de 8,8 a $18,7^{\circ} \mathrm{C}$, nestes mesmos meses (CORDEIRO, 2010). A precipitação pluvial anual média do Estado (período 1980-2009) é cerca de $1.672 \mathrm{~mm}$ (CORDEIRO, 2010), ocorrendo $27 \%$ deste total na primavera, $25 \%$ no outono, $24 \%$ no verão e $23 \%$ no inverno. Conforme Berlato e Cordeiro (2005), na metade norte do Estado (mais ou menos ao norte do paralelo de $30^{\circ} \mathrm{Sul}$ ), as precipitações pluviais anuais médias são superiores a $1.550 \mathrm{~mm}$ e na metade sul são inferiores a este valor. Também, as precipitações pluviais médias de todos os meses são maiores na metade norte do que na metade sul do Estado, principalmente, no nordeste do Estado (RIO GRANDE DO SUL, 2011).

No Rio Grande do Sul, a complexa diversidade geológica, climática e de relevo originou uma grande variedade de tipos de solos, com distintas características físicas e químicas, que refletem em diferentes aptidões de uso e manejo dos mesmos (STRECK et al., 2002). Na região de planaltos, em grande parte de derrames basálticos, em que predominam os Latossolos, profundos, de excelentes propriedades físicas e de fertilidade facilmente corrigível pela adubação e calagem, concentra-se a maior parte da produção de grãos do Rio Grande do Sul, tais como milho, soja e trigo. Essa região é muito suscetível à erosão, razão pela qual tem sido implantado, em larga escala, o sistema de plantio direto. Já nas planícies, os sistemas produtivos predominantes são a pecuária e a orizicultura. Solos como Gleissolos, Neossolos Flúvicos, Cambissolos (derivados de sedimentos fluviais), Planossolos, Plintossolos e Organossolos são os mais representativos desses ambientes (MANZATTO, 2002).

\section{Metodologia}

A base de dados de NDVI consta de uma coleção de imagens globais mensais de NDVI/AVHRR/ NOAA da série GIMMS, obtida gratuitamente via FTP (File Transfer Protocol) no endereço eletrônico da NASA $<$ http://ftp.glcf.umd.edu/data/gimms/>.

Cada imagem é uma Composição de Máximo Valor (CMV), construída a partir das imagens diárias do AVHRR de forma a reduzir a influência atmosférica. A preferência por imagens mensais e não pelas quinzenais (também disponíveis) visou minimizar possíveis efeitos de baixa qualidade de valores de NDVI, seja por serem valores fora do nadir ou por pixels com contaminação de vapor d'água.

As imagens NDVI/GIMMS têm Projeção Albers Equal Area Conic, elipsoide Clarke 1866, em coordenadas geográficas, datum WGS84 e resolução espacial de $8 \mathrm{~km}$ (aproximadamente $0,072^{\circ}$ ). As referidas imagens são reamostragens das imagens globais do projeto de monitoramento de cobertura da área global (Global Area Coverage - GAC) cuja resolução espacial é de 4 km (GLOBAL LAND COVER FACILITY, 2011). Portanto, a área de um pixel das imagens da série GIMMS representa 6.400 ha do terreno.

A área de estudo, compreendendo o Rio Grande do Sul, foi recortada e as imagens reprojetadas para o sistema de coordenadas geográficas "Lat Long". Foram geradas e aplicadas as máscaras para extração de corpos d'água, centros urbanos e limite do Estado, a partir de dados vetoriais obtidos dos mapas temáticos da base cartográfica do IBGE.

Foi utilizada a variabilidade temporal do NDVI no Rio Grande do Sul (conjunto de doze imagens mensais de janeiro a dezembro, médias dos 27 anos) para a análise de agrupamento dos pixels em regiões homogêneas, através da técnica "K-médias". Foram testados diferentes modos de inicialização de centroides (por partição aleatória, por pontos semente aleatória e pelo eixo diagonal) e, por fim, optou-se por utilizar este último.

A técnica "K-médias" utiliza a distância euclidiana para calcular as distâncias entre os pixels e os centroides de grupo. A partir de uma partição inicial mantém-se reatribuindo os objetos (valores de NDVI) aos grupos com base na similaridade entre os objetos e os centroides até que um critério de convergência seja satisfeito, este pode ser que não exista mais reatribuições de objetos de um grupo para outro, ou que o erro quadrático cesse de decrescer, significativamente, após algumas iterações. Neste trabalho, o critério 
estabelecido para encerrar o processo de agrupamento foi quando o percentual de migração dos pixels foi menor do que $1 \%$ dos pixels da imagem inteira, ou quando foi atingido o número máximo de 50 iterações. $\mathrm{O}$ agrupamento terminou quando uma das condições foi satisfeita. Também foi indicado para unir os pequenos grupos aos maiores.

Foram testados diferentes números de grupos (2 a 9 grupos). Mesmo definindo-se sete, oito ou nove grupos, o maior número de grupos formados foi de seis grupos. Após análise, o agrupamento dos pixels em seis regiões homogêneas (grupos) de NDVI foi usado para extração do NDVI mensal médio e confecção de gráfico com os perfis anuais médios do NDVI, de forma a caracterizar o padrão de variabilidade anual de cada grupo. Foram extraídos os valores do NDVI: mínimo, percentil 10, médio, percentil 90, máximo, coeficiente de variação (\%) da série de 324 meses e o coeficiente de variação anual (\%) para cada grupo vegetal do Rio Grande do Sul.

Foram adotados os sistemas computacionais: ENVI ${ }^{\circledR}$ para conversão das imagens globais mensais para o formato ".tif”; IDRISI ${ }^{\circledR}$ versão Taiga $($ Clark Labs () ) para confecção e execução de macros para importar imagens do formato ".tif" como ".rst", recorte da área de estudo, elaboração de máscaras e de imagens anuais, além do processamento digital de imagens nas operações relativas ao agrupamento pelo método de K-médias; e ArcGIS ${ }^{\circledR}$ para elaboração dos mapas temáticos.

\section{RESULTADOS E DISCUSSÃO}

Entre os agrupamentos testados, tendo como base a variabilidade temporal do NDVI, o que agrupou em seis regiões homogêneas foi considerado como o que melhor representou o uso e ocupação do solo do Rio Grande do Sul, nas últimas décadas. Como se pode observar na Figura 1, as regiões homogêneas de NDVI têm associação com as áreas do macrozoneamento ambiental (GUASSELLI et al., 2006). Isto fica evidenciado nas áreas deste macrozoneamento (Figura 2): de florestas remanescentes; campos mistos com florestas na Serra do Sudeste (campos mistos e subarbustivos); campos limpos; dunas no litoral; áreas agrícolas, principalmente a região maior produtora de grãos na metade Norte, áreas de cultivo de arroz na Depressão Central e em parte da Campanha; no Litoral e na parte Oeste do Estado.

A vantagem do agrupamento pela variabilidade temporal do NDVI é a praticidade do método, dispensando a necessidade de inúmeros planos de informação, como mapas de solo, altimetria, uso e ocupação do solo, entre outros, que em geral são necessários para confecção dos mapas temáticos. Nesse sentido, a análise de agrupamento se mostrou uma técnica de classificação de imagens de baixo custo, rápida, acessível e eficiente para agrupar as regiões homogêneas com a mesma variação temporal de NDVI.

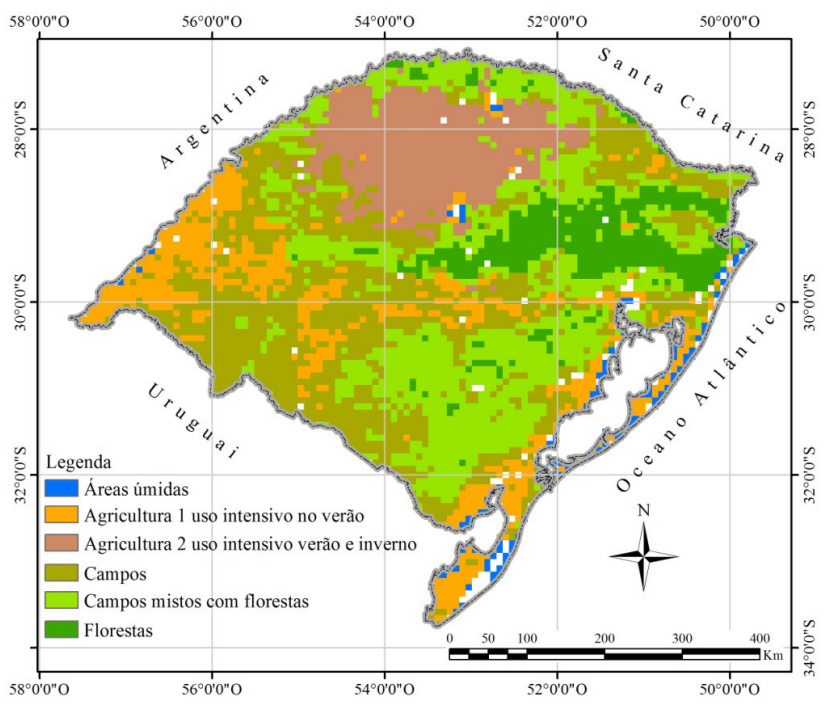

FIGURA 1: Regiões homogêneas quanto à variabilidade temporal de NDVI no Rio Grande do Sul.

FIGURE 1: Homogeneous regions according to NDVI temporal variability in the Rio Grande do Sul State. 


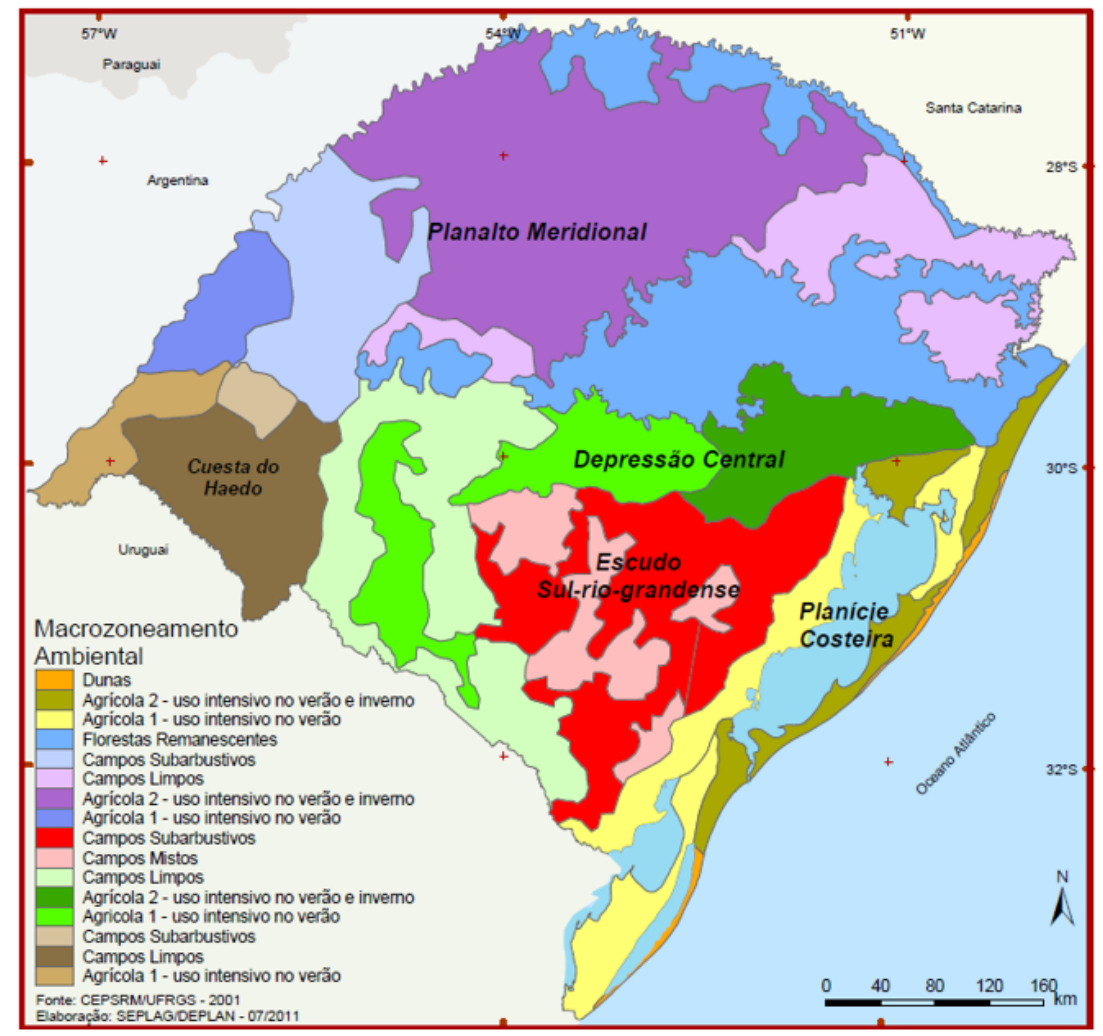

FIGURA 2: Macrozoneamento ambiental do Rio Grande do Sul. Fonte: Guasselli et al. (2006).

FIGURE 2: Environmental macrozoning of the Rio Grande do Sul State. Source: Guasselli et al. (2006).

O Grupo 1 foi identificado como Áreas úmidas, sendo os pixels deste grupo encontrados junto a corpos d'água como o Rio Uruguai, Rio Ibicuí, Rio Jacuí, Rio Passo Fundo, Rio Guaíba, Laguna dos Patos, Lagoa Mirim, Lagoa Mangueira e, principalmente, junto à costa do Litoral (Figura 3). O perfil anual médio de NDVI deste grupo foi o que apresentou os menores valores de NDVI. Os valores são menores no inverno e aumentam durante a brotação de novas folhas, atingindo o pico máximo de NDVI, em torno de 0,40 , em fevereiro, quando as plantas estão em pleno desenvolvimento vegetativo. Nos meses seguintes decresce (Figura 4).

O Grupo 2 ocupando parte do Baixo Vale do Uruguai, noroeste da Campanha, parte da Depressão Central, Zona Sul e proximidades da Laguna dos Patos, foi identificado como Agricultura 1 uso intensivo no verão. Estas são áreas tradicionalmente ocupadas, predominantemente, com o cultivo de arroz na primavera-verão e pousio com campos no outono-inverno (Figura 3).

Nas safras de 1990 a 2012, a área cultivada de arroz irrigado no Rio Grande do Sul, apesar de apresentar uma leve tendência de aumento, nunca ultrapassou 1.170.000 ha, registrados em 2011 (IBGE, 2014). No entanto, a área de cultivo de arroz agrupada pela variabilidade de NDVI é de 4.505 .600 ha, portanto, quatro vezes maior que a real área cultivada com arroz irrigado no Estado. Isto pode ser explicado pelo fato da área do Grupo 2 incluir áreas que alternam arroz e pousio com campos ou rotação de culturas com cultivos de sequeiro. Esta rotação de área compreende um período de três a quatro anos, que, na média de 27 anos, apresentam um mesmo padrão de variação e, portanto, caracterizaram um agrupamento diferenciado dos demais cultivos agrícolas. No entanto, a área agrupada pela variabilidade de NDVI se aproxima da área potencial de cultivo de arroz no Estado de 3.322.037 ha, determinada por Klering (2012) a partir da soma das áreas médias cultivadas com arroz irrigado nas safras de 2001 a 2010 no Rio Grande do Sul. Apesar de o agrupamento obtido das áreas cultivadas com arroz no Rio Grande do Sul não ser indicado para estimar/quantificar áreas, em função de sua resolução espacial, tal agrupamento se mostrou eficiente para definir uma área para extração do perfil médio de NDVI desse cultivo, bem como para retratar áreas 

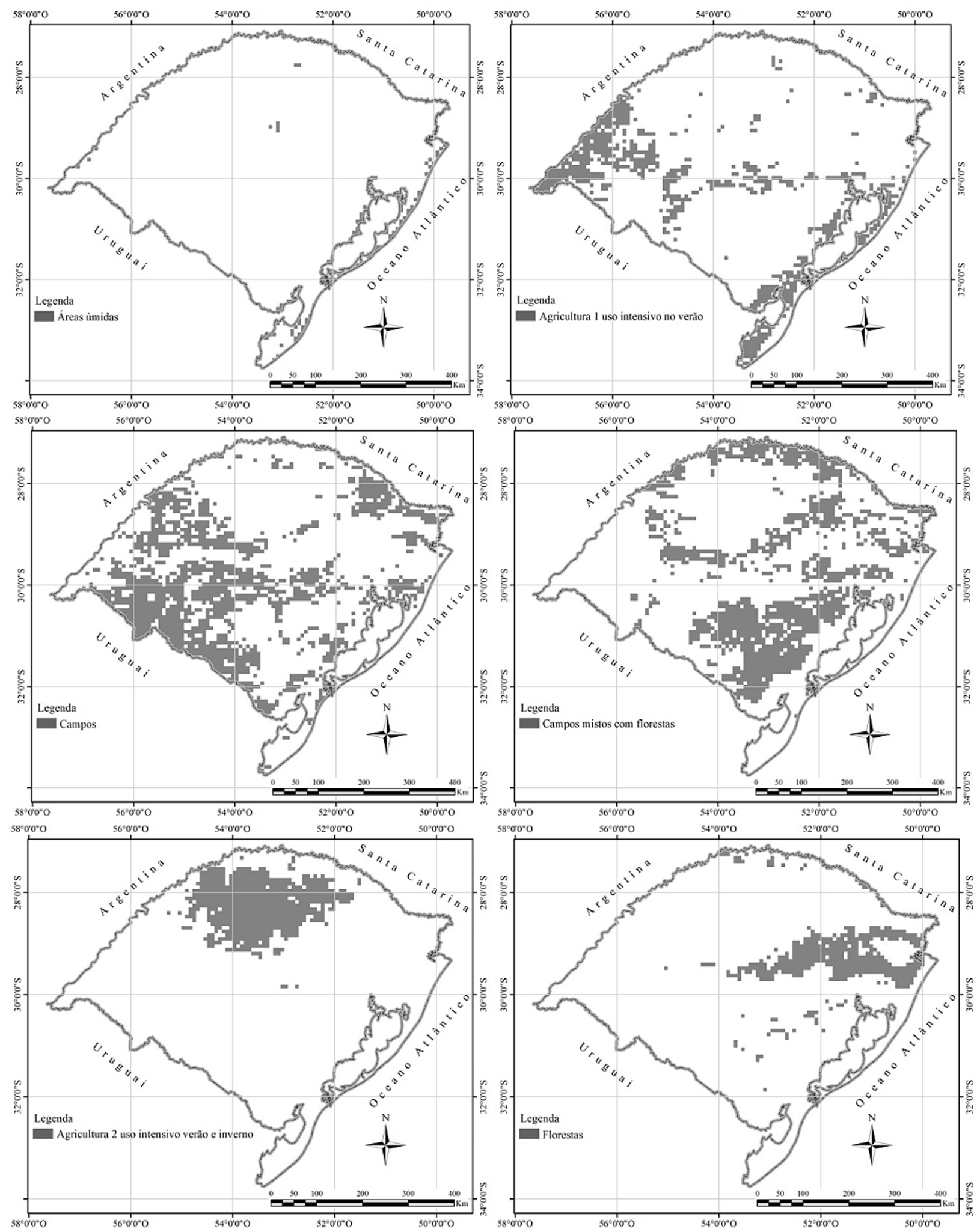

FIGURA 3: Grupos identificados como Áreas úmidas; Agricultura 1 uso intensivo no verão; campos; campos mistos com florestas; Agricultura 2 uso intensivo no verão e inverno; florestas.

FIGURE 3: Groups identified as Wetlands; Agriculture 1 intensive use in the summer; Grasslands; Grasslands mixed with forests; Agriculture 2 intensive use in the summer and in the winter; forests. 
potencialmente utilizadas para o cultivo do arroz.

O perfil anual médio de NDVI do Grupo Agricultura 1 uso intensivo no verão mostrou valores superiores aos observados no grupo Áreas úmidas, sendo crescentes a partir de julho. Seria esperado um decréscimo de NDVI nos meses de outubro e novembro, como consequência da entrada de água nas lavouras de arroz. Mas, o NDVI próximo a 0,60 , nestes meses, confirma a presença neste grupo da vegetação campestre (áreas de pousio), que, nesta época, encontra-se em estádio de brotação. O pico máximo de NDVI ocorre em fevereiro $(0,67)$, que corresponde aos estádios de floração e início de enchimento de grãos do arroz. O NDVI, então, decresce nos meses de outono, pela perda de biomassa verde e colheita do arroz (Figura 4). Apesar de limitações de caráter espacial, Tomita et al. (2000), na Tailândia, também mostraram ser possível monitorar os estágios de preparação de solo, desenvolvimento da cultura, maturação e colheita em uma área cultivada com arroz irrigado, a partir de perfis de NDVI gerados com imagens AVHRR.

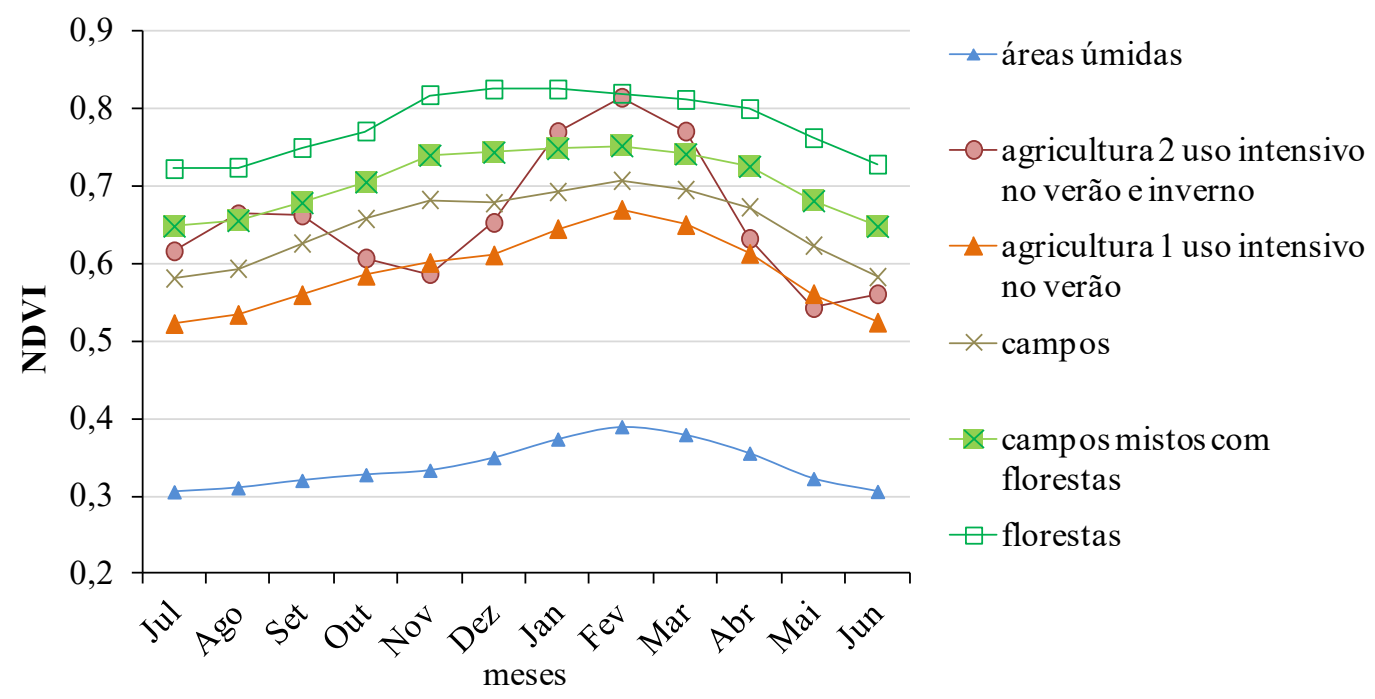

FIGURA 4: Perfil anual médio de NDVI dos grupos: Áreas úmidas; Agricultura 1 uso intensivo no verão; Campos; Campos mistos com florestas; Agricultura 2 uso intensivo no verão e inverno; e, Florestas. Estado do Rio Grande do Sul.

FIGURE 4: NDVI mean annual profile of the groups: Wetlands; Agriculture 1 intensive use in the summer; Grasslands; Grasslands mixed with forests; Agriculture 2 intensive use in the summer and in the winter; and forests; in the Rio Grande do Sul State.

O Grupo 3, identificado como áreas ocupadas com Campos, nativos ou cultivados, ocupa a maior parte do Rio Grande do Sul (Figura 3). Estes resultados estão em consonância com Overbeck et al. (2007), que relatam que os campos são a paisagem dominante no Rio Grande do Sul, cobrindo $75 \%$ do Estado, sendo que 62,2\% deste total está localizado no Bioma Pampa (BOLDRINI et al., 2010). Com valores de NDVI superiores aos anteriores, o perfil anual médio dos Campos (Figura 4) apresenta um pico mínimo no inverno, quando a vegetação está em senescência. As temperaturas baixas, dessa época do ano, causam a morte da parte aérea das gramíneas de grande parte da vegetação, resultando em baixa disponibilidade de biomassa (MACHADO, 1999), que se reflete na redução de NDVI. Nos meses de primavera, época de crescimento inicial das pastagens, o NDVI aumenta com um pico em novembro de 0,68 , quando a vegetação campestre encontra-se em brotação (MACHADO, 1999). No verão, o NDVI continua aumentando, devido ao crescimento da vegetação, como resposta ao aumento da temperatura (RIZZI; FONSECA, 2001). O pico máximo de NDVI ocorre em fevereiro $(0,70)$, quando a vegetação campestre se encontra com produção máxima de biomassa (MACHADO, 1999). A biomassa verde decresce nos meses de outono, quando se inicia a senescência.

Trentin e Fonseca (2011), utilizando série de 10 anos de imagens NDVI/MODIS para monitorar a fenologia da vegetação campestre do bioma Pampa, descreveram perfil anual médio semelhante a esse. A 
variação nos valores de NDVI dos Campos de 0,58 no inverno e 0,70 no verão foi semelhante à encontrada por Trentin e Fonseca (2011), 0,51 no inverno e 0,78 no verão. A equação do NDVI resulta em valores maiores quando há baixa reflectância na banda espectral do vermelho, devido à maior absorção da radiação solar pela maior quantidade de clorofila, e alta reflectância na banda do infravermelho próximo, devido ao espalhamento (reflectância e transmitância) da radiação no interior das folhas em função da estrutura celular (PONZONI; SHIMABUKURO, 2007). Por outro lado, quando o pico de reflectância é deslocado para a banda do vermelho, em função da degradação da clorofila e, a reflectância no infravermelho próximo diminui devido à degeneração das membranas celulares do mesófilo durante a senescência, ocorre uma diminuição nos valores de NDVI, conforme citado por Trentin e Fonseca (2011). A mesma explicação se aplica a variação nos valores de NDVI dos demais grupos vegetais, sendo maior ou menor a amplitude desta variação conforme as peculiaridades de cada grupo.

Estudando cinco zonas de campos no Rio Grande do Sul, Fontana, Almeida e Jacóbsen (2007) também verificaram menores valores de NDVI-AVHRR no outono e inverno e maiores valores do NDVI na primavera e verão, associados ao crescimento das plantas em resposta à temperatura e insolação. No entanto, no verão, período com maiores valores de NDVI, as diferenças entre as zonas foram mais bem evidenciadas, associadas à precipitação pluvial.

O Grupo 4 está presente na Serra do Sudeste e em áreas próximas à floresta Mata Atlântica, bem como no vale do Rio Uruguai e ao redor da região maior produtora de grãos. Tal fisionomia foi identificada como área de Campos mistos com florestas, justamente por conter, neste grupo, algumas florestas remanescentes da Mata Atlântica (Figura 3). A maior parte do Grupo 4 ocupa a Serra do Sudeste (Figura 3), a qual apresenta baixas temperaturas no inverno e compreende solos rasos Neossolos Litólicos, muito pedregosos, originados principalmente de granito, associados com Argissolos Vermelhos Amarelos. Muitas áreas, atualmente cobertas por vegetação campestre, eram originalmente ocupadas por subarbustos e árvores de baixo porte, que, aos poucos, foram cortados ou queimados (BOLDRINI et al., 2010). Também o mapeamento dos sistemas ecológicos da ecorregião das Savanas Uruguaias, realizado por Hasenack et al. (2010), classificou área semelhante na Serra do Sudeste, como Campo Arbustivo e Floresta Estacional, ambos com fisionomia dominante composta por um mosaico de floresta e campo.

Os Campos mistos com florestas apresentam um perfil anual médio semelhante aos Campos (Figura 4). Contudo, os valores de NDVI são mais altos por influência da vegetação florestal presente neste grupo, a qual apresenta maior vigor que a vegetação campestre. O pico mínimo de NDVI, no inverno, além da senescência da vegetação campestre, é influenciado também pela Floresta Estacional Semidecídua, presente neste grupo, que, com 20 a 50\% das espécies sendo caducifólias, perdem suas folhas nessa época de frio intenso (ROSEMBACK et al., 2010).

O Grupo 5 abrange 4.505.600 ha e foi identificado como Agricultura 2 uso intensivo no verão e inverno, pois são áreas ocupadas com cultivos para a produção de grãos, especialmente soja e milho na primavera-verão, e cereais de inverno, principalmente o trigo, no outono-inverno. Nesta região se concentra a maior produção de grãos do Rio Grande do Sul (Figura 3). Segundo o Acompanhamento de Safra de Grãos, a área cultivada com soja no Rio Grande do Sul foi de 4.618 .600 ha na safra 2013 (COMPANHIA NACIONAL DE ABASTECIMENTO, 2013). No entanto, a fronteira agrícola com esta commodity avançou em direção ao sul do Estado (COMPANHIA NACIONAL DE ABASTECIMENTO, 2013), incluindo áreas que não foram detectadas na metodologia utilizada no presente trabalho. Isto porque esta metodologia se baseia na variabilidade do NDVI ao longo de um ano médio de um período de 27 anos, e na maior parte desse período, apenas a área em destaque era a grande produtora de soja no Estado (RIZZI; RUDORFF, 2005; MELO et al., 2008). Na área identificada com Agricultura 2 uso intensivo no verão e inverno (Figura 3), além de soja também é cultivado o milho, o feijão e o girassol (COMPANHIA NACIONAL DE ABASTECIMENTO, 2013), cujas áreas são incompatíveis com o tamanho do pixel da série GIMMS. Segundo o Acompanhamento de Safra de Grãos, somando a safra e safrinha do milho, a área cultivada atingiu 1.033.300 ha (COMPANHIA NACIONAL DE ABASTECIMENTO, 2013), no entanto, distribuída em uma área bem mais abrangente do que a área da Figura 3. No outono-inverno são cultivados: trigo, aveia, cevada, canola, triticale e centeio. Segundo o Acompanhamento de Safra de Grãos na safra de 2013, o trigo ocupou uma área de 976.200 ha, a aveia 99.800 ha, a cevada 46.300 ha, a canola 28.200 ha, o triticale 5.200 ha, e o centeio 1.500 ha (COMPANHIA NACIONAL DE ABASTECIMENTO, 2013). No 
caso do trigo, aveia e cevada, a área de cultivo abrange parte do sul do Estado, extrapolando, assim, a área maior produtora de grãos.

Erros na totalização das áreas cultivadas são esperados em decorrência principalmente da resolução espacial de $8 \mathrm{~km}$ da série GIMMS. Mesmo trabalhando com a série MODIS, com resolução de $250 \mathrm{~m}$, Santos et al. (2014) afirmaram que a superestimativa de áreas de soja pode ser explicada pela resolução espacial destas imagens, em que pequenas áreas de soja vizinhas podem ter sido agregadas a uma grande área de soja no mapeamento. Por outro lado, a subestimativa de áreas pode ocorrer pela presença de pequenas áreas de soja, que não são detectadas pelo sensor MODIS e que também não apresentam padrão de agregação espacial.

Novamente é importante salientar que o agrupamento Agricultura 2 uso intensivo no verão e inverno não teve por objetivo mapear as lavouras, tendo em vista que, devido às diferentes características em relação ao tamanho, tecnologia de semeadura e calendário agrícola, este mapeamento deixaria muito a desejar ao utilizar imagens de baixa resolução. No entanto, o objetivo, de agrupar pixels com mesmo padrão de variabilidade de NDVI ao longo de um ano médio, a fim de extrair um perfil que descrevesse satisfatoriamente cada grupo vegetal, foi atingido.

O perfil anual médio do grupo Agricultura 2 uso intensivo no verão e inverno foi o que mais se diferenciou, dada a sua característica de apresentar dois picos máximos de NDVI. O primeiro ocorre quando os cultivos de outono-inverno atingem o máximo de biomassa, em agosto e setembro $(0,66)$, que correspondem aos meses de final do crescimento vegetativo e florescimento do trigo, que é o cereal predominante na maior parte da área (JUNGES; FONTANA, 2011). O NDVI decresce na época de colheita dos grãos dos cereais de outono-inverno, que na maior parte da área ocorre em novembro (JUNGES; FONTANA, 2011) e implantação das lavouras de primavera-verão, que, neste mês, apresenta forte resposta espectral do solo ou palha (WAGNER et al., 2007). O segundo máximo de NDVI ocorre em fevereiro $(0,80)$, que corresponde ao período de floração e/ou enchimento de grãos da soja, que é o cultivo dominante nesta época na região (RIZZI; RUDORFF, 2005; WAGNER et al., 2007; MELO et al., 2008; SANTOS et al., 2014). Neste período, a cultura apresenta a maior densidade de biomassa (MELO et al., 2008). Este pico apresenta valores mais altos que os cereais de inverno, pois a soja, sendo uma leguminosa, apresenta características de folha (SWAIN; DAVES, 1978), de arquitetura de planta e dossel diferentes dos cereais de inverno, que são gramíneas, fatores estes que influenciam a reflectância. Em março, quando tem início a época da colheita o NDVI é de 0,77 , decrescendo nos meses seguintes. O NDVI volta a aumentar a partir de maio, quando há a implantação do cultivo dos cereais de outono-inverno (JUNGES; FONTANA, 2011) na região (Figura 4).

O Grupo 6 foi identificado como áreas de Florestas (Figura 3), coerente com o macrozoneamento ambiental (Figura 2), em que área semelhante é classificada como Florestas remanescentes da Mata Atlântica. A maior parte do Grupo 6 coincide com as áreas mais declivosas do Estado. A parte leste superior, da região agrupada como Florestas, inclui a Floresta Ombrófila Mista; a parte leste inferior, a Floresta Estacional Semidecidual, que também é encontrada na Serra do Sudeste; e a parte inferior mais ao leste, inclui a Floresta Ombrófila Densa. Já na parte oeste da grande área agrupada como floresta e ao Norte do Estado encontra-se a Floresta Estacional Decidual. Embora as florestas da Mata Atlântica não tenham sido o foco do trabalho, no mapeamento das Savanas Uruguaias, com base em planos de informação obtidos de mapas temáticos de altitude, declividade, solos, vegetação e uso da terra, Hasenack et al. (2010) identificaram, como Florestas, áreas semelhantes às áreas agrupadas pela variabilidade do NDVI (Figura 3).

O perfil anual médio de NDVI das Florestas foi o que apresentou os valores mais altos entre os grupos analisados. Os valores são crescentes na primavera, que é a época de brotação, apresenta um pico no verão de 0,82 , quando a vegetação florestal encontra-se com produção máxima de biomassa verde, demonstrando maior vigor vegetativo (NORA; MARTINI, 2010), decrescendo nos meses de outono. O pico mínimo de NDVI ocorre no inverno, quando as temperaturas são baixas e a vegetação florestal encontra-se em repouso vegetativo, com perda parcial ou total de folhas (Figura 4).

Durante os meses de verão, em que a vegetação florestal se encontra com maior vigor, os valores de NDVI são maiores, devido à maior disponibilidade de pigmentos fotossintetizantes, absorvendo mais a radiação solar na faixa do vermelho e refletindo, fortemente, na faixa do infravermelho próximo, em decorrência da incapacidade dos estratos vegetativos em absorver ou transmitir este tipo de radiação 
(PONZONI; SHIMABUKURO, 2007). Por outro lado, durante o inverno, nas áreas de Florestas ocupadas pela Floresta Estacional Decidual e Semidecidual há perda de biomassa, o que reduz a oferta de pigmentos fotossintetizantes, e faz com que a reflectância na faixa do vermelho seja ligeiramente superior à observada no outono. Já a radiação na faixa do infravermelho, que passa a ser refletida apenas parcialmente, tem grande redução em sua reflectância (NORA; MARTINI, 2010). Com isto, a amplitude de variação entre os comprimentos de onda é reduzida e determina os valores mais baixos de NDVI durante os meses de junho, julho e agosto (Figura 4).

Ao avaliar a dinâmica sazonal de duas fitofisionomias florestais (Floresta Estacional Decídua e Floresta Ombrófila Mista) em duas unidades de conservação no Bioma Mata Atlântica (Parque Estadual do Turvo/RS e Parque Nacional das Araucárias/SC), Nora e Martini (2010) encontraram padrão fenológico do grupo florestas semelhante: menor NDVI nos meses de junho e julho e maior nos meses de verão. No entanto, as características decíduas distintas de cada formação florestal, alteram as relações de reflectância entre comprimentos de onda no vermelho e no infravermelho próximo, fazendo com que haja distintas variações sazonais entre as formações. No referido trabalho, a Floresta Estacional Decidual apresentou maior amplitude do índice. Isto ocorre porque, nesta formação florestal, a queda das folhas é mais intensa, principalmente durante a estação do ano mais severa (inverno), quando mais de $50 \%$ dos indivíduos arbóreos perdem suas folhas. Já a Floresta Ombrófila Mista apresenta maior perenidade, com a cobertura do dossel apresentando pouca ou nenhuma variação entre estações do ano (NORA; MARTINI, 2010).

Os resultados obtidos na análise de agrupamento de pixels que apresentam variabilidades de NDVI semelhantes, ao longo de um ano médio, mostraram ser possível agrupar distintos grupos vegetais em regiões homogêneas. Além disso, os perfis temporais médios de cada grupo descreveram satisfatoriamente a dinâmica da vegetação de cada grupo vegetal no Rio Grande do Sul. Estes resultados são importantes em sistemas de monitoramento da vegetação, especialmente pela facilidade de uso da metodologia e pela gratuidade das imagens. No monitoramento da vegetação natural ou com baixa influência antrópica, como banhados, campos ou florestas, a elaboração dos perfis pode ser útil em estudos de caso, em anos com forte ocorrência de condições adversas, como anomalias climáticas. E, no caso de programas de monitoramento agrícola pode-se, ainda, avaliar a variabilidade dos perfis entre as diferentes safras, servindo de subsídio para modelagem de biomassa.

Os valores médios anuais do NDVI (Tabela 1) evidenciam as diferenças de magnitude deste índice

TABELA 1: Valores do NDVI no período 1982-2008: mínimo, percentil 10, média anual, percentil 90, máximo, coeficiente de variação da série e anual (\%) para os grupos: Áreas úmidas; Agricultura 1 uso intensivo no verão; Campos; Campos mistos com florestas; Agricultura 2 uso intensivo no verão e inverno; e, Florestas, no Rio Grande do Sul.

TABLE 1: NDVI values in the period 1982 to 2008: minimum, 10th percentile, annual mean, 90th percentile, maximum, coefficient of variation of the series and annual (\%) for the groups: Wetlands; Agriculture 1 intensive use in the summer; Grasslands; Grasslands mixed with forests; Agriculture 2 intensive use in the summer and in the winter; and forests; in the Rio Grande do Sul State.

\begin{tabular}{lccccccc}
\hline \multicolumn{1}{c}{ Grupos } & Mínimo & Percentil 10 & Média anual & Percentil 90 & \multicolumn{2}{c}{ Máximo } & Coef. var. (\%) Coef. var. anual (\%) \\
\hline Áreas úmidas & 0,16 & 0,26 & 0,39 & 0,54 & 0,70 & 26,3 & 8,7 \\
$\begin{array}{l}\text { Agricultura 1 uso } \\
\text { intensivo no verão }\end{array}$ & 0,42 & 0,52 & 0,59 & 0,67 & 0,74 & 10,1 & 8,5 \\
$\begin{array}{l}\text { Campos } \\
\begin{array}{l}\text { Campos mistos com } \\
\text { florestas }\end{array}\end{array}$ & 0,47 & 0,56 & 0,65 & 0,72 & 0,81 & 9,8 & 7,1 \\
$\begin{array}{l}\text { Agricultura 2 uso } \\
\text { intensivo no verão e }\end{array}$ & 0,41 & 0,64 & 0,71 & 0,77 & 0,84 & 7,8 & 5,8 \\
$\begin{array}{l}\text { inverno } \\
\text { Florestas }\end{array}$ & 0,50 & 0,71 & 0,78 & 0,85 & 0,89 & 6,9 & 13,2 \\
\hline
\end{tabular}


entre os grupos. A menor média ocorreu nas Áreas úmidas $(0,39)$ e a maior nas Florestas $(0,78)$. Os grupos de Agricultura 1 e 2, Campos e Campos mistos com florestas apresentaram valores intermediários. As Áreas úmidas apresentaram ao longo da série o maior coeficiente de variação $(26,3 \%)$ dos grupos estudados, apesar do baixo coeficiente de variação anual $(8,7 \%)$. Esta alta variabilidade no grupo se deve a variações interanuais na lâmina d'água e no material em suspensão, que afetam fortemente a reflectância desses alvos. Depois do grupo Áreas úmidas, os grupos de Agricultura e Campos foram os que apresentaram maiores coeficientes de variação de NDVI. O Grupo Agricultura 2 uso intensivo no verão e inverno (áreas produtoras de grãos como soja, milho, trigo, entre outros cultivos) apresentou coeficiente de variação de NDVI de 15,0\%. Além disso, este foi o grupo que apresentou o maior coeficiente de variação anual de NDVI (13,2\%). Os menores coeficientes de variação foram verificados nos grupos Campos mistos com florestas $(7,8 \%)$ e Florestas $(6,9 \%)$. Estes valores estão de acordo com o esperado, já que a vegetação campestre apresenta menor tempo de resposta do que a vegetação florestal aos efeitos da variabilidade climática (WAGNER, 2013), principalmente no que se refere à precipitação pluvial. Por sua vez, a maior variabilidade interanual e anual dos cultivos agrícolas com grãos, como soja, milho e demais cultivos de primavera-verão, com relação aos Campos, Campos mistos com florestas e Florestas, também era esperada. Isto devido à alternância dessas áreas com os cultivos de outono-inverno em um mesmo ano, fato que resulta em maior coeficiente de variação, em relação a uma área que é sempre campo ou sempre floresta, ou ainda a combinação destas fisionomias.

\section{CONCLUSÕES}

A variabilidade de NDVI, obtida da série GIMMS/AVHRR, permite agrupar regiões homogêneas, de forma a identificar e mapear os principais grupos vegetais que ocorrem no estado do Rio Grande do Sul. Os grupos são caracterizados por um padrão sazonal típico, porém, com variações de amplitude de NDVI entre eles, o que possibilita monitorar as variações fenológicas da vegetação em decorrência da sua dinâmica temporal.

\section{REFERÊNCIAS}

BERLATO, M. A.; CORDEIRO, A. P. A. Variabilidade climática e agricultura do Rio Grande do Sul. In: AS ESTIAGENS e as perdas na agricultura: fenômeno natural ou imprevidência?. Esteio: FEDERACITE, 2005. p. 43-58.

BOLDRINI, I. I. et al. Bioma Pampa: diversidade florística e fisionômica. Porto Alegre: Pallotti, 2010. $64 \mathrm{p}$.

COMPANHIA NACIONAL DE ABASTECIMENTO (Brasil). Acompanhamento de safra brasileira: grãos, nono levantamento. 2013. Disponível em: <http://www.conab.gov.br/OlalaCMS/uploads/ arquivos/13_07_09_09_04_53_boletim_graos_junho_2013.pdf > . Acesso em: 11 mar. 2014.

CORDEIRO, A. P. A. Tendências climáticas das variáveis meteorológicas originais, estimadas e das derivadas do balanço hídrico seriado do Rio Grande do Sul. 2010. 273 f. Dissertação (Mestrado) - Programa de Pós-Graduação em Fitotecnia, Universidade Federal do Rio Grande do Sul, Porto Alegre, 2010.

DINIZ, G. B. et al. Identificação de regiões homogêneas de temperaturas máxima e mínima do Rio Grande do Sul. Revista Brasileira de Agrometeorologia, Santa Maria, v. 11, n. 2, p. 303-312, 2003.

DINIZ, G. B. Preditores visando a obtenção de um modelo de previsão climática de temperaturas máxima e mínima para regiões homogêneas do Rio Grande do Sul. 2002. 167 f. Tese (Doutorado em Fitotecnia) - Curso de Pós-graduação em Fitotecnia, Faculdade de Agronomia, Universidade Federal do Rio Grande do Sul, Porto Alegre, 2002.

FONTANA, D. C.; ALMEIDA, T. S.; JACÓBSEN, L. Caracterização da dinâmica temporal dos Campos do Rio Grande do Sul por meio de Imagens AVHRR/NOAA. Revista Brasileira de Agrometeorologia, Piracicaba, v. 15, n. 1, p. 69-83, 2007.

FONTANA, D. C.; BERLATO, M. A.; BERGAMASCHI, H. Relação entre o Índice de Vegetação Global e Condições Hídricas no Rio Grande do Sul. Pesquisa Agropecuária Brasileira, Brasília, v. 33, n. 8, 
p. 1399-1405, 1998.

GLOBAL LAND COVER FACILITY. [GIMMS Documentation NDVI]. [University of Maryland Global Land Cover Facility Data Distribuition], [2011]. Disponível em: <http:/glcf.umd.edu/library/guide/ GIMMSdocumentation_NDVIg_GLCF.pdf $>$. Acesso em: 07 nov. 2011.

GUASSELLI, L. A. et al. Macrozoneamento do Estado do Rio Grande do Sul. Pesquisas em Geociências, Porto Alegre, v. 33, n. 1, p. 03-11, 2006.

GURGEL, H. C. Variabilidade espacial e temporal do NDVI sobre o Brasil e suas conexões com o clima. 2000. 118 f. Dissertação (Mestrado em Sensoriamento Remoto) - Curso de Pós-graduação em Sensoriamento Remoto, São José dos Campos, 2000.

GURGEL, H. C.; FERREIRA, N. J.; LUIZ, A. J. B. Estudo da variabilidade do NDVI sobre o Brasil, utilizando-se a análise de agrupamentos. Revista Brasileira de Engenharia Agrícola e Ambiental, Campina Grande, v. 7, p. 85-90, 2003.

HASENACK, H. et al. Mapa de sistemas ecológicos da ecorregião das savanas uruguaias em escala 1:500.000 ou superior e relatório técnico descrevendo insumos utilizados e metodologia de elaboração do mapa de sistemas ecológicos. Porto Alegre: UFRGS - Centro de Ecologia The Nature Conservancy, 2010. 22 p. (Relatório Técnico).

IBGE. Anuário estatístico do Brasil. Rio de Janeiro: IBGE, 2011. 474 p. v. 71. Disponível em: $<$ http://biblioteca.ibge.gov.br/visualizacao/monografias/GEBIS\%20-\%20RJ/AEB/AEB2011.pdf>. Acesso em: 05 jun. 2014.

IBGE. Resolução n 05, de 10 de outubro de 2002. 2002. Disponível em: <http://www.ibge.gov.br/home/ geociencias/areaterritorial/principal.shtm>. Acesso em: 14 mar. 2012.

IBGE. SIDRA - Sistema IBGE de Recuperação Automática. 2014. Disponível em: <http://www.sidra. ibge.gov.br/bda/tabela/protabl.asp?c=1612\&z=t\&o=11\&i=P>. Acesso em: 09 mai. 2014.

JUNGES, A. H.; FONTANA, D. C. Modelo agrometeorológico-espectral de estimativa de rendimento de grãos de trigo no Rio Grande do Sul. Revista Ceres, Viçosa, MG, v. 58, n. 1, p. 9-16, 2011.

KLERING, E. V. Mapeamento da área cultivada e estimativa do rendimento de grãos de arroz irrigado a partir de modelos agrometeorológicos- espectrais para o Rio Grande do Sul. 2012. $163 \mathrm{f}$. Tese (Doutorado em Fitotecnia) - Curso de Pós-graduação em Fitotecnia, Faculdade de Agronomia, Porto Alegre, 2012.

KÖPPEN, W. Climatología. México: Fondo de Cultura Económica, 1948. 71 p.

LYRA, G. B. et al. Regiões homogêneas e funções de distribuição de probabilidade da precipitação pluvial no Estado de Táchira, Venezuela. Pesquisa Agropecuária Brasileira, Brasília, v. 41, n. 2, p. 205-215, 2006.

MACHADO, L. A. Z. Manejo da pastagem nativa. Guaíba: Agropecuária, 1999. 158 p.

MANZATTO, C. V. Uso agrícola dos solos brasileiros. Rio de Janeiro: Embrapa Solos, 2002. 174 p. Disponível em: <http://www.cnps.embrapa.br/publicacoes/pdfs/uso_agricola_solos_brasileiros.pdf $>$. Acesso em: 14 jan. 2014.

MARQUES, J. R. Variabilidade espacial e temporal de precipitação pluvial no Rio Grande do Sul e sua relação com indicadores oceânicos. 2005. 210 f. Tese (Doutorado em Fitotecnia) - Curso de Pósgraduação em Fitotecnia, Faculdade de Agronomia, Porto Alegre, 2005.

MELO, R. W. et al. An agrometeorological-spectral model to estimate soybean yield, applied to southern Brazil. International Journal of Remote Sensing, London, v. 29, n. 14, p. 4013-4028, 2008.

MIRANDA, J. I. Processamento de imagens digitais: métodos multivariados em Java. Campinas: Embrapa Informática Agropecuária, 2011. 400 p.

MOTTA, J. L. G.; FONTANA, D. C.; WEBER, E. Análise da evolução temporal do NDVI/NOAA em região de soja no Rio Grande do Sul. In: SIMPÓSIO BRASILEIRO DE SENSORIAMENTO REMOTO, 11., 2003, Belo Horizonte. Anais...São José dos Campos: INPE, 2003. p. 197-204.

NORA, E. L. D.; MARTINI, D. Z. Análise da dinâmica sazonal de fitofisionomias do bioma Mata Atlântica com base em índices de vegetação do sensor MODIS/Terra. Ambiência, Guarapuava, v. 6, n. 1, p. 97-108, 2010.

OVERBECK, G. E. et al. Brazil's neglected biome: The South Brazilian Campos. Perspectives in Plant Ecology, Evolution and Systematics, Jena, v. 9, p. 101-116, 2007. 
PONZONI, F. J.; SHIMABUKURO, Y. E. Sensoriamento Remoto no estudo da vegetação. São José dos Campos: Parêntese, 2007. 127 p.

RIO GRANDE DO SUL. Secretaria de Planejamento, Gestão e Participação Cidadã. Atlas socioeconômico do Rio Grande do Sul. Porto Alegre, 2011. Disponível em: <http://www.scp.rs.gov.br/atlas/default.asp $>$. Acesso em: 17 jan. 2011.

RIZZI, R.; FONSECA E. L. Análise da variação espacial e temporal do NDVI no Estado do Rio Grande do Sul através de imagens AVHRR. In: SIMPÓSIO BRASILEIRO DE SENSORIAMENTO REMOTO, 10., 2001, Foz do Iguaçu. Anais...São José dos Campos: INPE, 2001. p. 1735-1737.

RIZZI, R.; RUDORFF, B. F. T. Estimativa da área de soja no Rio Grande do Sul por meio de imagens Landsat. Revista Brasileira de Cartografia, Rio de Janeiro, v. 57, n. 3, p. 226-234, 2005.

ROSEMBACK, R. et al. Análise da dinâmica da cobertura vegetal na região sul do Brasil a partir de dados MODIS/Terra. Revista Brasileira de Cartografia, Rio de Janeiro, nesp 2, n. 62, p. 401-416, 2010.

ROUSE, J. W. et al. Monitoring vegetation systems in the Great Plains with ERTS. In: EARTH RESOURCES TECHNOLOGY SATELLITE SYMPOSIUM, 3., 1973, Washington. Proceedings... Washington: NASA, 1973. p. 309-317.

SANTOS, J. S. et al. Identificação da dinâmica espaço-temporal para estimar área cultivada de soja a partir de imagens MODIS no Rio Grande do Sul. Revista Brasileira de Engenharia Agrícola e Ambiental, Campina Grande, v. 18, n. 1, p. 54-63, 2014.

STRECK, E. V. et al. Solos do Rio Grande do Sul. Porto Alegre: EMATER/RS; UFRGS, 2002. 126 p.

SWAIN, P. H.; DAVIS, S. M. Remote sensing: the quantitative approach. New York : McGraw-Hill, 1978. $396 \mathrm{p}$.

TOMITA, A. et al. Vegetation patterns in the Chao Phraya Delta, 1997 dry season using satellite image data. In: CHAO Phraya Delta: Historical development, dynamics and challenges of Thailand's rice bowl. Bangkok: [s. n.], 2000.

TRENTIN, C. B.; FONSECA, E. L. Monitoramento da fenologia da vegetação campestre do bioma Pampa e sua relação com a temperatura média do ar. In: SIMPÓSIO BRASILEIRO DE SENSORIAMENTO REMOTO, 15., 2011, Curitiba. Anais...São José dos Campos: INPE, 2011. p. 1628.

WAGNER, A. P. L. et al. Estimativa de área de soja no Rio Grande do Sul utilizando imagens NDVI/ MODIS. In: SIMPÓSIO BRASILEIRO DE SENSORIAMENTO REMOTO, 13., 2007, Florianópolis. Anais...São José dos Campos: INPE, 2007. p. 457-464.

WARD, J. H. Hierarchical grouping to optimize an objective function. Journal of American Statistical Association, Texas, v. 58, n. 301, p. 236-244, 1963. 